\title{
The Design Method of Aggregate Gradation of AC-25 Asphalt Mixture Based on Road Performance
}

\author{
Zhaohui SUN ${ }^{1, a}$ Tiebin WANG ${ }^{2, b}$ Zefeng WU ${ }^{3, c}$ Deying YU ${ }^{4, d}$
}

1.The Transportation Engineering School of Shenyang Jianzhu University, Shenyang,110168,China

2.Liaoning Provincial Traffic Engineering Quality and Safety Supervision Bureau, China

3. Highway Administration Bureau of Liaoning Provincial Communications Department

\section{Shenyang Road Administrative Bureau}

happyforevernicety@126.com, tiebinwang2004@163.com, zefengwu@126.com, deyingyu@126.com

Keywords: AC-25 asphalt mixture; Design Method; Road performance; Prediction model;Gradation test; Evaluation index; Fractal dimension; Range

Abstract. The road performance prediction models of AC-25 asphalt mixture are established through a large number of road performance test, the road performance of AC-25 asphalt mixture is predicted in the design calculation process. The gradation test prediction models are established to identify the skeleton structure type of asphalt mixture. The asphalt mixture design method based on road performance is proposed on the basis, which makes the asphalt mixture achieve the optimal in the design process and reduce the unnecessary test amount.

\section{Introduction}

Asphalt mixture design is one of the important factors that affect the asphalt pavement performance, and good gradation is an important guarantee for high quality road performance. The design work of asphalt mixture is done well is the basis and premise to ensure that the asphalt pavement has good road performance. Aiming at the characteristics of climate, materials and transportation in the northeast region, the design method of asphalt mixture based on road performance is proposed by applying the fractal theory.The AC-25 asphalt mixture design method proposed is discussed in detail. The raw material performance test

Liaohe petroleum asphalt grade A No.90, which is widely used in the northeast of China.The coarse and fine aggregate of AC-25 mixture use limestone gravel produced by Liaoyang Xiaotun victory quarry. Grade A No.90 road petroleum asphalt and limestone were tested in accordance with the requirements of the road usage.

\section{Road performance test}

The 25 groups of AC-25 asphalt mixture were designed by orthogonal test method, and the rutting test, water stability test and low temperature performance test were carried out under the conditions of tire ground pressure $0.84 \mathrm{MPa}$. The results of the experiment are shown in table 1.

\section{High temperature performance test}

The technical requirements for the dynamic stability of asphalt mixture rutting test are different according to different climate zones and the type of asphalt and mixture in the current specification, Climate zoning in the Northeast of China is belonging to the 2-1 area (hot in summer and severe cold in winter) and 2-2 area (hot in summer and cold in winter), due to the wheel pressure 0.84 MPa was adopted in rutting test, dynamic stability should be reduced from relevant literature to meet greater than or equal to 667 times / mm. Therefore, the high temperature stability of AC-25 mixture with the grading number of $4 、 10 、 11 、 12 、 15 、 17 、 18 、 20$ and 25 can meet the requirements.

\section{Water stability test}

The dynamic stability ratio of asphalt mixture was proposed to evaluate the water stability of it.The dynamic stability ratio is defined as the ratio of the dynamic stability of the specimen after freezing thawing cycles and the dynamic stability of non freezing and thawing cycles specimen. ${ }^{[5]}$ 
Table 1 The results of AC-25 road performance test

\begin{tabular}{|c|c|c|c|c|c|}
\hline Gradation & $\mathrm{D}$ & $\mathrm{D}_{\mathrm{c}}$ & $\mathrm{D}_{\mathrm{f}}$ & $\begin{array}{c}D S_{0} \\
\text { Times/mm }\end{array}$ & DSR \\
\hline AC-25-4 & 2.4495 & 2.3906 & 2.4877 & 678 & 0.86 \\
\hline AC-25-12 & 2.4917 & 2.5823 & 2.4256 & 800 & 0.88 \\
\hline AC-25-15 & 2.6117 & 2.3046 & 2.5689 & 722 & 0.83 \\
\hline AC-25-17 & 2.5973 & 2.5915 & 2.5581 & 1104 & 0.83 \\
\hline AC-25-18 & 2.5607 & 2.5098 & 2.5809 & 719 & 0.82 \\
\hline AC-25-20 & 2.4641 & 2.3147 & 2.3781 & 671 & 0.88 \\
\hline
\end{tabular}

The AC-25 mixture which aggregate gradation number is 4, 12, 15, 17, 18 and 20 meet simultaneously the requirements of high temperature and the water stability .

\section{Low temperature performance test}

Because of the low temperature in winter in the Northeast area, it is prone to arise sudden changes of temperature and large temperature difference between day and so on, the low temperature performance requirements of asphalt mixture is high. The low temperature performance needs to meet the technical requirements of the specification in the Northeast region. The low temperature bending test is done by the microcomputer controlled test system for asphalt mixture according to E20 JTG 2011 "Standard Test Methods of bitumen and bitumious mixtures for highway Engineering." (T0715) ,the test result are shown in table 2.

Table 2. The fractal dimension of AC-25 asphalt mixture and the low temperature test data

\begin{tabular}{|c|c|c|c|c|c|c|c|}
\hline $\begin{array}{c}\text { Gradation } \\
\text { number }\end{array}$ & $\begin{array}{c}\text { Average } \\
\text { maximu } \\
\text { m load } \\
(\mathrm{N})\end{array}$ & $\begin{array}{c}\text { Average } \\
\text { span } \\
\text { deflectio } \\
\mathrm{n}(\mathrm{mm})\end{array}$ & $\begin{array}{c}\text { Bending } \\
\text { strain } \varepsilon_{\mathrm{B}} \\
(\mu \varepsilon)\end{array}$ & $\begin{array}{c}\text { Bending } \\
\text { strength } \\
\mathrm{Mpa}\end{array}$ & $\mathrm{D}$ & $\mathrm{D}_{\mathrm{c}}$ & $\mathrm{D}_{\mathrm{f}}$ \\
\hline AC-25-6 & 704 & 1.3 & 7017 & 5.28 & 2.4264 & 2.6333 & 2.4352 \\
\hline AC-25-8 & 692 & 0.56 & 3039 & 5.27 & 2.5922 & 2.4913 & 2.5689 \\
\hline AC-25-9 & 586 & 1.2 & 6580 & 4.35 & 2.5767 & 2.3998 & 2.5259 \\
\hline AC-25-13 & 315 & 0.59 & 3851 & 3.57 & 2.4441 & 2.5005 & 2.5130 \\
\hline AC-25-15 & 689 & 1.18 & 6372 & 5.28 & 2.6117 & 2.3046 & 2.5689 \\
\hline AC-25-18 & 908 & 1.04 & 5894 & 7.32 & 2.5607 & 2.5098 & 2.5809 \\
\hline AC-25-20 & 321 & 0.76 & 3960 & 2.68 & 2.4641 & 2.3147 & 2.3781 \\
\hline AC-25-22 & 892 & 0.51 & 2855 & 6.27 & 2.4382 & 2.6100 & 2.5414 \\
\hline AC-25-24 & 1132 & 0.62 & 3408 & 7.63 & 2.6156 & 2.4366 & 2.5940 \\
\hline AC25-GC & 735 & 0.73 & 3982 & 6.57 & 2.5798 & 2.3332 & 2.5809 \\
\hline
\end{tabular}

\section{Road performance prediction model}

Asphalt mixture high temperature stability, water stability and low temperature stability are important road performance of asphalt pavement, if we can establish the correlation model between the fractal

Table 3 Prediction model of AC-25 mixture road performance

\begin{tabular}{|l|lll|}
\hline \multicolumn{1}{|c|}{ Road performance name } & \multicolumn{1}{c|}{ Prediction model } & \multicolumn{2}{c|}{ Regression coefficient $\mathrm{R}^{2}$} \\
\hline High tempreture & $\mathrm{DS}=823.6+651.1 \mathrm{D}+361.2 \mathrm{D}_{\mathrm{c}-390.0 \mathrm{D}_{\mathrm{f}}}$ & 0.8530 \\
\hline Low tempreture & $\varepsilon_{\mathrm{B}}=31584+29277 \mathrm{D}+2929 \mathrm{Dc}-42435 \mathrm{D}_{\mathrm{f}}$ & 0.9590 \\
\hline Water stability & $\mathrm{DSR}=1.650-0.048 \mathrm{D}+0.011 \mathrm{D}_{\mathrm{c}}-0.283 \mathrm{D}_{\mathrm{f}}$ & 0.9590 \\
\hline
\end{tabular}

dimension of asphalt mixture and the evaluation index of high temperature stability, water stability and low temperature stability and the road performance of asphalt mixture can be predicted through 
the gradation fractal dimension to reduce the amount of test work. The prediction models of the high temperature performance, water stability and low temperature performance are established by applying MATLAB software and analyzing the correlation between the fractal dimension and the evaluation indexes such as dynamic stability, dynamic stability ratio and low temperature bending failure strain, the road performance prediction models of asphalt mixture are recommended through multiple model comparison. They are shown in table 3.

The fractal parameters ranges for AC-25 asphalt mixture meeting the road performance requirements

The rutting test results of meeting the above high temperature stability requirements in the Northeast of China and the corresponding fractal dimension are summarized in Table 1.

The fractal dimension of 25 group gradations meeting asphalt mixture high temperature stability, low temperature performance and water stability were aggregated, the fractal dimension ranges which meet the road performance requirements of asphalt mixture are obtained, the fractal dimension ranges are shown in Table4.

Table4 The fractal dimension ranges for AC-25 asphalt mixture meeting the road performance requirements

\begin{tabular}{|c|c|c|c|}
\hline Technical requirement & $\mathrm{D}$ & $\mathrm{D}_{\mathrm{c}}$ & $\mathrm{D}_{\mathrm{f}}$ \\
\hline High temperature & $2.4495-2.6117$ & $2.3046-2.5915$ & $2.3781-2.5809$ \\
\hline Low temperature & $2.4264 \sim 2.6156$ & $2.3046 \sim 2.6333$ & $2.3781 \sim 2.5940$ \\
\hline Water stability & $2.4495 \sim 2.6117$ & $2.3046 \sim 2.5915$ & $2.3781 \sim 2.5809$ \\
\hline Comprehensive performance & $2.4495-2.6117$ & $2.3046-2.5915$ & $2.3781-2.5809$ \\
\hline
\end{tabular}

According to the requirements of various technical performance in the Northeast of China, Reference to the road performance requirements in the current specifications, draw on the experience of the previous research results of the research group, the technical performance requirements of AC-25 modified asphalt mixtures are proposed in the Northeast of China, as is shown in Table 5.

Table5 The technical requirements of AC-25 asphalt mixture road performance in the Northeast of China

$$
\text { Performance name The technical requirements }
$$

$\begin{array}{cl}\text { High temperature performance } & \mathrm{DS} \geq 667 \text { times/mm } \\ \text { Low temperature performance } & \varepsilon_{\mathrm{B}} \geq 2300 \mu \varepsilon \\ \text { Water stability } & \mathrm{DSR} \geq 0.80\end{array}$

The inequality is listed according to the technical requirements of asphalt mixture in the northeast region of China.As is shown in inequality (1).

$$
\left\{\begin{array}{l}
D S=823.6+651.1 D+361.2 D_{C}-390.0 D_{f} \geq 667 \\
\varepsilon_{B}=31583.6+29277 D+2929 D_{C}-42435.5 D_{f} \geq 2300 \\
D S R=1.650-0.048 D+0.011 D_{C}-0.283 D_{f} \geq 0.8
\end{array}\right.
$$

Using MATLAB programming to get the solution of inequality.

The range of fractal dimensions is: $\mathrm{D}_{\mathrm{f}} \leq 2.3799, \mathrm{D} \geq-2.8524$, Dc is no solution. According to the proposed method, the range of fractal dimension is $\mathrm{Df} \leq 2.4192, \mathrm{D} \geq-2.8524$, and $\mathrm{Dc}$ is no solution..

In order to avoid the blindness of selecting the fractal dimension in the design process, the fractal dimension ranges which meet the requirements of various performance techniques are proposed .It is suggested that the aggregate gradation fractal dimension $\mathrm{D}$ is in the range of $2.4495 \sim 2.6117$, the coarse aggregate fractal dimension is in the range of 2.3046 2.5915, and the fine aggregate fractal dimension Df is in the range of 2.3781 2.4192.

\section{Design method of asphalt mixture based on road performance Selection of fractal dimension}

On the basis of the preliminary work of the research group, the fractal dimension of gradation meeting the requirements of the high temperature stability, low temperature performance and water stability in 
25 group gradation is summarized, the fractal dimension range of meeting asphalt mixture road performance requirements is obtained.

\section{.Aggregate pass rate derivation}

The quality distribution of asphalt mixture has fractal characteristics, the quality distribution function of aggregate is shown in the formula (2).

$$
P(r)=\frac{r^{3-D}-r_{\min }^{3-D}}{r_{\max }^{3-D}-r_{\min }^{3-D}}
$$

$\mathrm{P}(\mathrm{r})$ is pass rate of sieve size $\mathrm{r}$ in the aggregate of maximum size $\mathrm{r}_{\max }(\%)$.

If the fractal dimension is known, the pass rate of seives can be calculated and analyzed by the formula (3).

When the fractal dimension of the aggregate particle size distribution is calculated by using the nominal maximum size NMPS of aggregate, the formula (3) can be adjusted to the formula (3).

$$
P(r)=\frac{r^{3-D}-r_{\min }^{3-D}}{N M P S^{3-D}-r_{\min }^{3-D}} P_{0}
$$

Formula: $P_{0}$ is the pass rate of the nominal maximum size NMPS, take $90 \%--100 \%$.

$\mathrm{D}$ is the fractal dimension of aggregate particle size distribution, which is hereafter referred to as aggregate gradation fractal dimension.

Therefore, it can be infered that the formula (4 can be established when $\mathrm{r}$ lies between PCS and NMPS, namely, When $r \in(P C S, N M P S$ ),formula (5) is established.

$$
P(r)=\frac{r^{3-D_{C}}-r_{\min }^{3-D_{C}}}{N M P S^{3-D_{C}}-r_{\min }^{3-D_{C}}}
$$

$$
\text { When } r \in(0.075, \quad P C S) \text {, formula (5) is established. }
$$

$$
P(r)=\frac{r^{3-D_{f}}-r_{\min }^{3-D_{f}}}{P C S^{3-D_{f}}-r_{\min }^{3-D_{f}}} \times P(P C S)=\frac{r^{3-D_{f}}-r_{\min }^{3-D_{f}}}{P C S^{3-D_{f}}-r_{\min }^{3-D_{f}}} \times \frac{P C S^{3-D_{C}}-r_{\min }^{3-D_{C}}}{N M P S^{3-D_{C}}-r_{\min }^{3-D_{C}}} \times P_{0}
$$

Formula, PCS is the size of boundary points of coarse and fine aggregates;NMPS is normal maximum particle sieve size. $r_{\min }$ is the smallest particle size;Dc is the coarse aggregate grading fractal dimension which particle size is in the range of NMPS to PCS , $\mathrm{D}_{\mathrm{f}}$ is the fine aggregate grading fractal dimension which particle size is in the range of PCS and $0.075 \mathrm{~mm}$.

As $r_{\min }$ tends to 0 , and the pass rate of $r_{\min }$ is approximately 0 , to simplify the formula, the $r_{\min }^{3-D}$ of the formula (5) and (6) is given up to get the simplified formula, as is shown in formula (7) and (8).

When $r \in(P C S, N M P S$ ), formula (6) is established.

$$
P(r)=\left(\frac{r}{N M P S}\right)^{3-D_{c}} \cdot P_{0}
$$

For continuous grading, the particle distributing between $0.075 \mathrm{~mm}$ and NMPS (nominal maximum size) is a fractal distribution, that is, only a fractal dimension D can describe the distribution of aggregate particles.

\section{Road performance prediction}

The high temperature stability, low temperature stability and water stability of GAC-20 mixture were predicted by the performance prediction model established in Table 5. In the forecast model, the forecast value of each index is calculated by fractal dimension $\mathrm{D}, \mathrm{Dc}$ and $\mathrm{D}_{\mathrm{f}}$. The fractal dimension is reselected in the recommended range if the road performance evaluation index can not meet requirements until the prediction results are satisfied with the performance requirements of the road. 


\section{Grading test}

According to the previous research results, the correlation model between the fractal volume parameter and the fractal dimension is established to test gradation.The prediction and test are done when the fractal dimension of coarse and fine aggregate meeting the road performance requirements are substituted to these prediction models of coarse aggregate fractal void volume Vco and fractal volume of fine aggregate in coarse aggregate $V_{f}$, the coarse aggregate can form an effective framework when coarse aggregate fractal void volume Vco is larger than the fractal volume of fine aggregate in coarse aggregate $\mathrm{V}_{\mathrm{f}}$, the fractal dimension is adjusted to form a skeleton if the skeleton is not formed. The prediction model of fractal volume parameters is shown in table 6 .

Table 6 The Prediction Model of Fractal Volume Parameter

\begin{tabular}{ll}
\hline \multicolumn{1}{c}{ Grading test index } & $\begin{array}{l}\text { Prediction model } \\
\text { parametersR }\end{array}$ \\
\hline Coarse aggregate fractal void $^{2}$ & $\mathrm{~V}_{\mathrm{co}}=0.065+0.939 \mathrm{D}-0.196 \mathrm{D}_{\mathrm{c}}-0.684 \mathrm{D}_{\mathrm{f}}$ \\
volumeV $_{\text {co }}$ & 0.561 \\
Fractal volume of fine aggregate in & $\mathrm{V}_{\mathrm{f}}=-0.184+0.002 \mathrm{D}+0.306 \mathrm{D}_{\mathrm{c}}-0.182 \mathrm{D}_{\mathrm{f}}$ \\
coarse aggregate $\mathrm{V}_{\mathrm{f}}$ & 0.978 \\
$\mathrm{~V}_{\mathrm{co}} \geq \mathrm{V}_{\mathrm{f}}$ & $0.249+0.937 \mathrm{D}-0.502 \mathrm{D}_{\mathrm{c}}-0.502 \mathrm{D}_{\mathrm{f}} \geq 0$ \\
\hline
\end{tabular}

\section{Test and Inspection}

The high temperature stability, low temperature performance, water stability and other performance of AC-25 asphalt mixture are tested for grading meeting the above steps, the design of the grading is qualified if all the requirements are meet, otherwise, the reasons should be timely found and corrected, or the gradation is redesigned in accordance with the above method steps until the requirements are meet.

\section{Conclusion}

Based on the previous work, the design method of AC-25 asphalt mixture based on road performance in Northeast of China was put forward.

The fractal dimension for meeting the road performance requirements will be taken as a design parameter by applying the fractal theory and each sieve passing rate is deduced by the fractal dimension. The road performance of AC-25 asphalt mixture can be predicted by using the performance prediction model established, the gradation skeleton structure are test by using the fractal volume parameters prediction model. Finally, the asphalt mixture which meet the predictive road performance requirements was tested to get excellent performance gradation.

\section{References}

【1】 Occupation Standard of the People's Republic of China., JTG E20-2011 "Standard Test Methods of Bitumen and Bituminous Mixtures for Highway Engineering" [S]

【2】 Highway Science Research Institute, Ministry of Communications JTG F40-2004 "Technical Specifications for Construction of Highway Asphalt Pavements" [S]

【3】 Occupation Standard of the People's Republic of China, JTG E42-2005 "Test Methods of Aggregate for Highway Engineering", [S]

【4】 Nukunya,B., R.Roque,M.Tia,B. Birgisson. Evaluation of VMA and other Volumetric Properties as Criteria for the Design and Acceptance of Superpave Mixtures[J].Journal of the Association of Asphalt Paving Technologists, Vol.79,pp.38-69(2002)

【5】Zhao-Hui SUN, Tie-Bin WANG, Ze-Feng WU and Zhi-Song WANG, Research on the Evaluation Method of Water Stability for Large Size aggregate Particle Asphalt Mixture Applied Mechanics and Materials Vol. 692 (2014) pp 497-500 Submitted: 10.09.(2014) 
【6】Zhao-hui SUN De-ying YU Tie-bin WANG Guang-qiang ZHU The water stability prediction model of AC-25 modified asphalt mixture, advances in Engineering 2017,(100):110-115

【7】 SUN Zhaohui, YANG Guofeng, YU Baoyang WANG Tiebin Study on the Gradation Inspection Methold Based on Fractal Theory[J] JOURNAL OF SHENYANG JIANZHU UNIVERSITY (NATURAL SCIENCE) Vol.26 No.5 875-880 2010

【8】Zhao-hui Sun, Qing Li , Meng-meng Li,Han-yang Chen.Low temperature performance predic tion model of GAC-20 modified asphalt mixture 